\title{
Confinement duration on rewarded and nonrewarded trials and patterning at 24-hour ITI ${ }^{1}$
}

\section{THOMAS SURRIDGE AND ABRAM AMSEL UNIVERSITY OF TORONTO}

Rats were trained on a single alternating schedule of partial reinforcement for 134 days, one trial a day. Patterning did not develop in any of three goalbox confinement conditions: long on nonreward and short on reward trials; short on nonreward and long on reward trials; and short on both nonreward and reward trials.

Surridge \& Amsel (1966) failed to obtain patterning in a single-alternation schedule of reinforcement run at $24 \mathrm{~h}$ intertrial intervals (ITIs). This failure has been attributed by Capaldi \& Lynch (1966) to the short (30 sec) duration of nonreward confinement time (NC) employed by Surridge and Amsel. Capaldi and Lynch obtained one-trial-a-day patterning when NC was $120 \mathrm{sec}$ but not when NC was $30 \mathrm{sec}$; their confinement duration on rewarded trials (RC) was $30 \mathrm{sec}$ in both conditions.

The Capaldi and Lynch result seemed so important to us that we decided to rerun their experiment under our own conditions, simply as a guide to our future research. It also occurred to us that patterning at $24 \mathrm{~h}$ ITIs may not only be a matter of long confinement time on nonrewarded (N) trials relative to that on rewarded (R) trials, but rather differential confinement on $R$ and $N$ trials. We therefore included a group given $30 \mathrm{sec}$ NC and $120 \mathrm{sec}$ RC along with the two groups of Capaldi and Lynch.

Method

Twenty-seven male albino rats, approximately 60-70 days of age, were maintained on a $23 \mathrm{~h}, 10 \mathrm{~g}$ food deprivation schedule for 20 days prior to experimental training, during which time they were handled and tamed.

A straight, $5 \mathrm{ft} 3$ in. wooden runway, with a gray entry box and start box, was employed. The runway was painted flat white on the left half, flat black on the right half. Five $1 \mathrm{ft}$ time measures of performance were provided by means of a microswitch on the start door and five photobeams located in the runway. Interruption of the final photobeam activated a pellet dispensing device located outside the end wall of the goalbox.

Ss were randomly assigned to one of three groups, all of which received a single alternating schedule of $\mathbf{R}$ and $\mathrm{N}$ trials. Group NC30-RC30 was confined in the goalbox for 30 sec following both $N$ and $R$ trials; Group NC120-RC30 was confined 120 sec on $N$ trials and $30 \mathrm{sec}$ on R trials; and Group NC30-RC120 was confined $30 \mathrm{sec}$ on $\mathbf{N}$ trials, $120 \mathrm{sec}$ on $\mathrm{R}$ trials.

All $\mathrm{Ss}$ received a total of 134 trials, one trial a day.
Reward was one $500 \mathrm{mg}$ Noyes pellet. All the odd numbered days were rewarded, the even numbered days nonrewarded. Half the Ss from each group started the experiment on Day 1, the other half on Day 2. Therefore, following Day 2, there was always the same number of $R$ and $N$ trials given on any one day. The order of running the Ss was randomized from day to day.

$\mathrm{S}$ was taken from its home cage in the colony room to the experimental room and placed in the entry box for 5 sec. The entry box door was then raised and lowered when $S$ entered the start box. The start box door was raised approximately 2 sec later. When $S$ had interrupted the final photobeam the goalbox door was lowered, and $S$ was removed after the appropriate confinement time and returned to the home cage after the apparatus had been reset for the next trial.

The daily ration of food was given to all Ss $30-40 \mathrm{~min}$ after the testing of the last S.

\section{Results}

Figure 1 presents the speed data from the goal measure ( $\mathrm{ft} / \mathrm{sec}$ ) for each group on the last 30 days of training (15 $\mathrm{R}$ and $15 \mathrm{~N}$ trials).

There was no consistent tendency for slower performance on $\mathrm{N}$ trials in any group. This was confirmed by analyses of variance performed on reciprocals of raw scores for each group and each of the five runway mea-

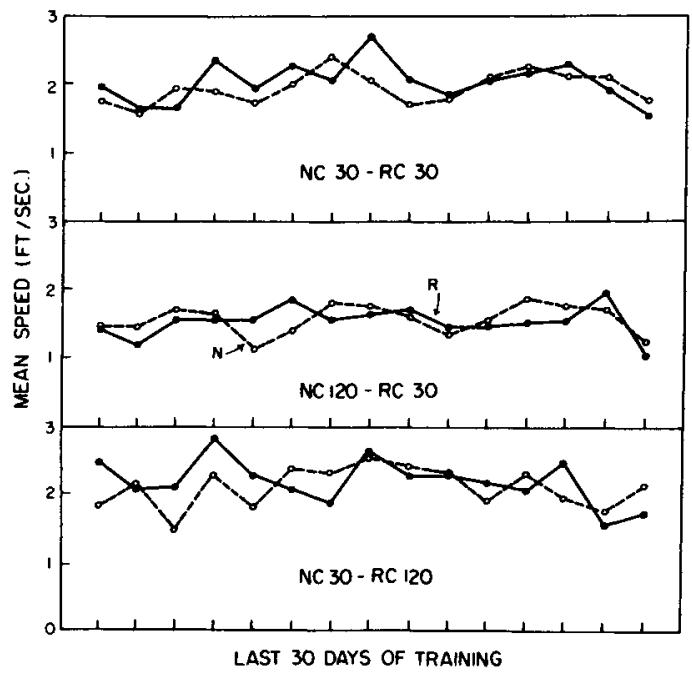

Fig. 1. Mean goal entry speeds on the last 30 days of training (15N, 15R trials). 
sures, comparing performance on $\mathrm{R}$ and $\mathrm{N}$ trials over the final 30 training days. The $\mathrm{R}-\mathrm{N}$ differences were not significant in any measure ( $p>.05$ in all cases). Discussion

Group NC30-RC30 did not pattern, confirming the results of Capaldi \& Lynch (1966) and of Surridge \& Amsel (1966). Contrary to the finding of Capaldi and Lynch, however, Group NC120-RC30, the group given long confinement on nonreward trials, did not exhibit patterned performance.

There were only two items of procedure in Capaldi and Lynch's study which seemed very different from ours. First, Capaldi and Lynch placed $S$ in a black box for $30 \mathrm{sec}$ before and after each trial, while in our experiment $S$ was introduced directly into the entry box, and returned to its home cage immediately after it had completed each trial. It is difficult to see, however, how this difference could have accounted for the discrepancy in the two results. The second procedural difference seems a more likely candidate: Capaldi and Lynch employed $30 \mathrm{sec}$ access to wet mash as reward, while we used a $500 \mathrm{mg}$ dry food pellet. It may be that the use of a very large reward, even larger than the one we used, as well as a very long $\mathrm{NC}$, are among the factors necessary to produce patterning at $24 \mathrm{~h}$ ITIS. This suggestion has been advanced by Capaldi (1967).

Capaldi (1967) has also suggested that Surridge and Amsel's failure to obtain $24 \mathrm{~h}$ ITI patterning may be related to the fact that "reward was present in the goalbox on nonrewarded trials" (p. 137), since the floor under the goalbox was always littered with food crumbs, not visible or available to $S$, the presence of which presumably could be detected by $\mathrm{S}$. Of course, this was a procedure we used in order to reduce the likelihood of patterning on the basis of olfactory discrimination. According to Capaldi, "if on the nonrewarded trial the animal sees, smells, or otherwise detects the reward (but of course does not consume it), the stimulus on the succeeding trial may not be $\mathrm{SN}$ but something quite different. In that event, the discrimination between ' $\mathrm{S}$ ' ' and $\mathrm{S}^{\mathrm{R}}$ would be increased and patterning would be more difficult to obtain" (1967,p. 137). Notwithstanding this view, Capaldi and Lynch made special provision to ensure that $S$ could detect the presence of a "highly pungent mash" located under their goalbox and still obtained patterning. We would therefore assume that the presence of "reward" on nonreward trials is not a factor which influences the development of patterned performance.

Capaldi and Lynch obtained patterning; we did not. The reason for this discrepancy, apparent or real, is still not entirely obvious.

\section{References}

CAPALDI, E. J. A sequential hypothesis of instrumental learning. In $\mathrm{K}$. W. Spence and J. Spence (Eds.) Recent advances in learning and motivation. New York: Academic Press, 1967.

CAPALDI, E. J., \& LYNCH, D. Patterning at 24hour ITI: Resolution of a discrepancy more apparent than real. Psychon. Sci., 1966, 6, 229-230.

SURRIDGE, C. T., \& AMSEL, A. Acquisition and extinction under single alternation and random partial-reinforcement conditions with a 24hour intertrial interval. $J$. exp. Psychol, 1966, 72, 361-368. Note

1. Supported by research grants GB-3772 from the National Science Foundation and APB-72 from the National Research Council of Canada. 